\title{
LIX. Notices respecting new books
}

\section{Donovan}

To cite this article: M. Donovan (1817) LIX. Notices respecting new books, Philosophical Magazine Series 1, 49:227, 218-220, DOI: $10.1080 / 14786441708637890$

To link to this article: http://dx.doi.org/10.1080/14786441708637890

曲 Published online: 27 Jul 2009.

Submit your article to this journal $2 \pi$

Џ Article views: 2

Q View related articles $₫$ 
such a degree of perfection. The press which M. Engelmann uses, is described as "c different from all other presses;" but we are not aware of any thing which can be wanted in point of force and equality of compression, that may not be obtained by means of the ordinary copperplate or rolling presses; by the latter especially, which upon the whole we should think will be found best adapted to the lithographic process.

In order to ascertain the full value of this invention, it remains still to be known whether any given number of impressions equally beautiful can be taken, and what that number is. In the first essays of the art, it is certain that a very great inequality in the impressions was experienced; and although it is said that M. Engelmann has devised means of apportioning with the most scrupulous exactness the quantity of the different ingredients, and of retouching his designs from time to time, no results are stated to enable us to form a satisfactory conclusion on the points we have stated.

It would be also desirable to know at what price the lithographist can furnish his impressions, since this must have no small influence on the success of any competition between them and engravings.

\section{Notices respecting New Boaks.}

$\mathrm{N}$ Treatise on the general Principles of Chemical Analvsis; with Plates and valuable Additions from his Elements of Chemistry, \&c. forming one octavo volume.

A Second Edition of The Amusements in Retirement; or, The Influence of Science and the Arts on the Manners and Happiness of Private Life, will be published in a few days.

Sir William Adams is about to publish A Practical Inquiry into the Causes of the frequent Failure of the Operations of cxtracting and depressing the Cataract, and the Description of a new and improved Series of Operations, by the Practice of which most of these Causes of Failure may be avoided.

A new Fdition of Dr. Thomson's System of Chemistry is in the press, and will speedily be published. The work will be entirely remodelled, and will be comprised in four octavo volumes.

Dr. Leach, of the British Museum, has recently printed a very complete Catalogue of Birds and Quadrupeds which are natives 
of Great Britain. It is perhaps the most correct catalogue which in our present imperfect knowledge of British ornithology has been as yet compiled. But he has made (we do not know on what authority) very considerable alterations in the old arrangement, and composed a variety of new English generic names.

A catalogue has likewise just issued from the press, entitled Catalogus Avium in Insulis Britannicis halitantium, curâ et studio Edwardi Forsteri jun. This is merely a catalogue of birds discovered wild in Great Britain. Mr. Forster differs also in this catalogue in his arrangement from the arrangement and names of Linneus. He enumerates 293 species.

Another new work On the pernicious Influence of Wine and fermented and spirituous Liquors in general, is about to be pub. lished ; containing Preliminary observations on the principles of health, and on the extensive application of the doctrine maintained by $\mathrm{Mr}$. Abernethy (in part i. of his Surgical Observations respecting the sympathetic influence of the digestive organs) to the different genera and species of diseases; and on the periodical influence of atmospheric causes on our health.

Mr. J. Robertson, of Surry House Academy, Kennington Cross, will in a few days publish A Practical Example Book on the Use of Maps; containing problems and exercises to be worked and filled up by students in geography. Designed as an auxiliary to that study for the use of schools and private students.

An interesting pamphlet " On the Accidents which occur in the Mines of Cornwall, in consequence of the premature Explosion of Gunpowder in blasting Rocks, and on the Methods to be adoptẹd for preventing it, by John Ayrton Paris, M.D.F.L.S." has just made its appearance.

The same gentleman is now preparing for publication A Deseriptive Catalogue of the Geological Specimens deposited in the Museum of the Royal Geological Society of Cornwall; interspersed with observations tending to show the oeconomical applications of geology to the agricultural, mining, and commercial interests of the county of Cornwall. This work will form one volume octavo.

To Mr. Tilloch.

SIR,-I beg the favour of correcting, through the medium of the Philosophical Magazine, a typographical error in my Essay on Galvanism recently published, which entirely destroys the sense and force of the experiment, and which heretofore escaped my attention. The passage, beginning page 277 , line 26 , runs 
thus: "the other wire was inserted into a disc of copper, in a similar mauner." It should be read, "the other wire was inserted into a dise of corl, in a similar mamer."

1 hope that such readers of your Magazine as have copies, will take the trouble to correct the error.

Dublin, March 13, 1817 .

I am, sir, with respect, \&c.

M. Donovan.

\section{Lx. Proceedings of Learned Socielies.}

ROYAL SOCIETT.

Feb. 27. Ar the instance of the President, Sir E. Home furnished some descriptive observations on the fossil bones found by Mr. Whitby, the superintendant of the works, in the quarry whence the stone for the Plymouth Break-water is extracted, These bones were found about 70 feet below the surface of the ground, and four above high-water mark, in a cavern which is nearly opposite to, and at a little distance from, the works now carrying on at Plymouth. The bones are more perfect, and freer from extraneous matter, than any other fossil bones hitherto found. The cavern has no incrustations on its sides, no external communication, and no appearance of infiltration; its bottom, in which the bones were deposited, is filled with clay, three feet of which covered them. The bones found by Mr. Whitby, and sent by him to Sir Joseph Banks, belonged to three different animals of the rhinoceros species, and are larger than those in Mr. Brooks's Museum. According to Mr. Brande's analysis, they contain little but the usual contents of bones, and have very little earthy or extraneous matter. It appears that there are two kinds of stone used in constructing the Break-water, and that the one being much harder than the other, a different price is paid for raising it; but the part in which the bones were found is of the harder kind, and for which the greatest price is paid for quarrying.

March 6. The Rev. Mr. Hyde Wollaston gave the Society a description of an instrument which he has lately invented for measuring altitudes, and which he calls a thermometrical barometer. Every one who has attempted to use the common mountain barometer has experienced the difficulty, and almost impossibilicy, of preserving it without fracture. To remedy this, Mr. Wollaston, observing the striking difference in the temperature of water according to the atmospheric pressure, instituted a series of experiments, in order to construct a thermometer which should answer all the purposes of measuring heights with ex- 